PSICOLOGIA, SAÚDE \& DOENÇAS, 2021, 22(2), 636-644

ISSN - 2182-8407

Sociedade Portuguesa de Psicologia da Saúde - SPPS - www.sp-ps.pt

DOI: http://dx.doi.org/10.15309/21psd220226

\title{
IMPACT OF BURNOUT SYNDROME IN ATHLETES: RELATIONSHIP BETWEEN SEX, AGE, AND SPORT
}

\author{
Rafael Rodrigues ${ }^{1}$, Vinicius Hirota ${ }^{2}$, Willer Maffei ${ }^{3}$, José Pedro Ferreira ${ }^{1}, \&$ Carlos Verardi ${ }^{3}$ \\ ${ }^{1}$ Faculty of Sports Science and Physical Education, University of Coimbra, Coimbra, Portugal, \\ Rafael.nogueira@unesp.br,jpferreira@fcdef.uc.pt \\ ${ }^{2}$ Department of Physical Education, UniAnchieta University Center, Jundiai, Brazil, vbhirota@gmail.com \\ ${ }^{3}$ School of Sciences, Campus Bauru, Physical Education Department, São Paulo State University (UNESP), Bauru, \\ São Paulo, Brazil,willer@unesp.br, verardi@unesp.br
}

\begin{abstract}
Burnout syndrome has a multidimensional characteristic, and there are feelings inherent to this syndrome, and it has different response due to characteristic of the athletes and their sport. The purpose of the present study was to identify burnout levels and its relationship between sex, age and type of sport. The Athletes Burnout Questionnaire (ABQ) was used to assess the prevalence of burnout in athletes and whether burnout is influenced by sex, age group, and type of sport (individual versus team sports). The ABQ was administered to 223 athletes (50 females $(15,4 \pm 4,17$ years old) and 173 males (17,8 $\pm 4,34$ years old)) in 4 different sports modalities (swimming, gymnastics, basketball, and soccer). The results showed that between $1 \%$ and $9 \%$ of the athletes showed elevated burnout scores on these four subscales, and the hypothesis of higher prevalence of burnout in individual sports was supported someway, by athletes who had higher levels of Emotional and Physical Exhaustion when compared to those of team sports. It was also found that age did not influence burnout levels. Furthermore, only a no correlation between sex and burnout scores was found. These findings suggest that factors other than sex, and age must be considered when athletes at risk for burnout are investigated.
\end{abstract}

Keywords: Burnout, athletes, sport, sex, age

\section{IMPACTO DA SÍNDROME DE BURNOUT EM ATLETAS: RELAÇÃO ENTRE SEXO, IDADE E ESPORTE}

RESUMO: A síndrome de Burnout tem uma característica multidimensional, e há sentimentos inerentes a síndrome, bem respostas diferentes devido às características dos atletas e de seus esportes. O presente estudo teve o propósito de identificar níveis de burnout e sua relação entre sexo, idade e tipo de esporte. O Questionário de Burnout para Atletas (ABQ) foi utilizado para avaliar a prevalência de burnout em atletas, e qual a influência relativa ao sexo, idade e tipo de esporte (individual versus esportes coletivos). O ABQ foi administrado a 223 atletas (50 mulheres (15,4 $\pm 4,17$ anos) e 173 homens $(17,8 \pm 4,34$ anos)) em 4 modalidades esportivas diferentes (natação, ginastica, basquete e futebol). Os resultados demonstraram que entre $1 \%$ e $9 \%$ dos atletas

Travessa da Rua Velha, nº. 3, 5 esq., São Bartholomeu, Coimbra, 3040-242 Portugal. Email: Rafael.nogueira@unesp.br 
apresentaram escores elevados de burnout nas quatro subescalas, e a hipótese de maior prevalência de burnout nos esportes individuais foi sustentada, pois os atletas de esportes individuais apresentaram níveis mais altos de exaustão emocional e física quando comparados aos esportes coletivos. Também foi constatado que a idade não influenciou os níveis de burnout. Além disso, não houve correlação entre os escores de sexo e burnout. Esses dados sugerem que outros fatores além do sexo e da idade devem ser considerados quando atletas com risco de burnout são investigados.

Palavras-Chave: Burnout, atletas, esporte, sexo, idade

Recebido em 08 de fevereiro de 2020/ Aceite em 23 de maio de 2021

Burnout syndrome has a multidimensional characteristic, and involves three components: "Emotional Exhaustion", with feelings of extreme fatigue and perceived inability to "donate" affectively; "Depersonalization", with the development of cynical attitudes and negative feelings, and "Dissatisfaction with Professional Achievement", with the tendency to evaluate negatively, especially in relation to users or clients, with feelings of unhappiness and dissatisfaction with one's own work (Maslach \& Jackson, 1981; Weinberg \& Gould, 2018). According to (Weinberg \& Gould, 2018) burnout involves a psychological, emotional and sometimes physical escape from pleasurable acts in response to an excessive level of stress or dissatisfaction related to their work and conceptualize the burnout syndrome in sports as a psychophysiological response of exhaustion, exhibited as a result of frequent effort, and ineffective in to satisfy the excessive demands of training and competition.

In relation to the type of sport, the feelings inherent to the syndrome are generally more observed in athletes of individual sports than in athletes of team sports due to the division of functions and tasks that occur in the collective ones, besides to the greater number of interpersonal relationships existing in team sports (Smucny et al., 2015). However, studies on this subject still need to be better investigated, and in some studies (dos Santos et al., 2014; Verardi et al., 2014) show that the position/function of the athlete within the team also influences stress and burnout levels, showing a broader problem in the collective ones.

Meanwhile, when the theme is linked to the age of the athletes and the burnout syndrome, studies are even more scarce. The syndrome is well described when it comes to the adult population, but in children and adolescents there are only a few studies (Brenner et al., 2016, 2007). According to the (American Academy of Pediatrics, 2000), high training loads and early specialization are great precursors, and the resulting manifestations are the same as in the adult population - demotivation, fatigue, high heart rate, decreased performance and disinterest in sports. In the study by (Gustafsson et al., 2007), which evaluated 980 young athletes from 29 sports modalities, was observed high burnout scores in around $9 \%$ of them, and the hypothesis presented by the (American Academy of Pediatrics, 2000) on high training loads was not found in this study, since no correlation was found between elevated burnout scores and training loads, which again shows the multifactorial status of this syndrome and the difficulty of establishing a pattern.

In a review (Goodger et al., 2007), it was verified that female athletes presented higher rates of Emotional and Physical Exhaustion in $73 \%$ of the publications on the subject, while among the indexes of Reduced Sense of Accomplishment and Sports Depreciation there were no significant differences between the sexes.

Based on these considerations, we can verify the lack of studies and some limitations regarding the syndrome in different contexts, the comparison between male and female athletes, the comparison between team and individual sports, or the relationship between burnout and the age group of these athletes. Therefore, the lack of consensus in the literature on these aspects justifies the present study. 
Thus, the aim of the present study was to identify and compare burnout levels among athletes practicing individual and team sports in three specifics folds: i) to assess hypothetical burnout differences between gender; ii) between age groups; and iii) between types of sports (individual versus team).

\section{METHODS}

\section{Sample}

The sample was intentional, not probabilistic, for convenience, and consisted of 223 athletes, aged between 10 and 35 years, of which 173 were males, with a mean age of 17,8 $\pm 4,34$ years and 50 females, with a mean age of 15,4 $\pm 5,17$ years, 108 were from individual modalities (79 of artistic gymnastics; 29 of swimming) and 115 of collective modalities (49 basketball; 66 soccer).

\section{Instruments}

The Burnout Questionnaire for Athletes (ABQ) validated for the Portuguese language by (Pires et al., 2006), from the English language instrument entitled Athlete Burnout Questionnaire (Raedeke \& Smith, 2001). This questionnaire consists of 15 Likert-type questions, which 05 is about the Emotional and Physical Exhaustion (EPE) subcategory (I am exhausted by the physical and emotional demands of the sport), being number 2, 4, 8, 10, and 12; 05 to measure the subcategory Sport Devaluation (SD) (I have negative feelings about sports), being numbers 3, 6, 9, 11 and 15; and 05 to measure the subcategory Reduced Sense of Accomplishment (RSA) (no matter what I do, I do not perform as I should), with issues numbers 1, 5, 7, 13 and 14. Each of the questions has 5 possible answers, the number 1 is "I almost never feel that way" and the other extreme, the number 5, means "I feel this way most of the time", and the intermediate responses are as follows: "Rarely "(2)," Sometimes "(3) and" Often "(4). It is a self-applicable instrument, with the average response time around twenty minutes, and has a general internal consistency index (Cronbach's coefficient $\alpha$ ) equal to 0.82 , a value considered satisfactory, because the minimum accepted value was 0.70 , and the individual analyzes of the instrument validation study indicated that all 15 items of the questionnaire reached the necessary scores for the validation of the internal consistency. In addition, the $\alpha$ values obtained in each of the items were smaller than the general coefficient (0.82). By showing that, if any item is removed from the questionnaire, the reliability index of the instrument would be reduced, confirming the relevance of all 15 items to maintain a high reliability. Therefore, according to (Pires et al., 2006), the Burnout Questionnaire for Athletes is considered reliable and of satisfactory internal consistency, that is, there is a homogeneity among its components.

\section{Procedures}

In contact with the athletes, these were informed about the research, its objectives, and its methodology. Soon after, the Informed Consent Form was handed over to those responsible, with the purpose of clarifying the conditions for participation in the research. The condition of participation in the research was the return of the Term of Informed Consent, duly signed by the person in charge. 
The data were collected personally by the researchers before each training session during the precompetitive phase of the season. The athletes who accepted the condition for participation in the research were interviewed and instructed to answer the questionnaires at the training site.

This study was approved by the Research Ethics Committee of the College of Sciences of the São Paulo State University (UNESP), under the number 323,400. Preceding the data collection was requested the permission to develop the research, together with the responsible professionals of the participating teams, and presented the objectives and methodology to be used during the study.

\section{Data Analysis}

First, the Mann - Whitney U test was performed. For the variables that the Mann-Whitney U test was applied, a 95\% bootstrap confidence interval was calculated for the mean of each group. For the calculation and analysis of the data of Burnout Total and its subscales (Reduced Sense of Accomplishment (RSA), Emotional and Physical Exhaustion (EPE), Sport Devaluation (SD)) was used descriptive and interference statistics for comparative studies. Estimates of mean, standard deviation, median, quartiles and extreme values were calculated and compared, considering the differences between groups. The results attributed to each subscale were obtained from the arithmetic mean of the answers given to the five items corresponding to each dimension of burnout (RSA, EPE, SD), and the total burnout value was calculated by the arithmetic mean of all 15 items. To verify the internal consistency of the Burnout Questionnaire for Athletes, the Cronbach alpha coefficient $(\alpha)$ was used for the values of the Total Burnout variable. The level of significance adopted in all statistical procedures of this study was $\mathrm{p} \leq 0.05$.

\section{RESULTS}

Together with the initial statistical analysis, the Cronbach alpha test was performed for the Burnout Total variable (BT), obtaining a result of 0.95 , which shows satisfactory internal consistency and homogeneity of the sample for the questionnaire used. The results related to each of the items (modality, gender, and age) are presented initially in general, and then an analysis of the vulnerability to the syndrome identified in this sample.

Table 1 presents the descriptive measures of the scores related to the Burnout Questionnaire for Athletes, for each dimension - Reduced Sense of Accomplishment (RSA), Emotional and Physical Exhaustion (EPE) and Sport Devaluation (SD), as well as Burnout Total (BT - represented by the general mean) stratified by the modality variable.

Among the 3 specific variables of the questionnaire, the Reduced Sense of Accomplishment (RSA) had the highest score, both in the group of collective modalities (RSA $=2.66 \pm 0.46$ ) and in individual modalities $(\mathrm{RSA}=2.86 \pm 0.49$ ), followed $\mathrm{EPE}$, with values for team and individual modalities, were $1.82 \pm 0.69$ and $2.15 \pm 0.77$, respectively, however there is a detail to observe with caution, in this variable there are subjects with maximum scores (Value $=5$ ). In the variable Sport Devaluation (SD), we have the lowest score for both groups. It should be noted that, in relation to the type of modality, the mean and median values for the Reduced Sense of Accomplishment (RSA), Emotional and Physical Exhaustion (EPE), Sport Devaluation (SD) and burnout total (BT) were always higher for the group of individual modalities, which shows evidence of greater vulnerability among the individuals practicing this type of sports modality.

Table 2 below presents the hypothesis tests, the p-value of the normality test in each group, the $\mathrm{p}$-value for the hypothesis test in relation to the modalities and the Confidence Interval (CI) for each modality in relation variables. 
Table 1. Average score for the three subscales and the burnout total value for both sports groups.

\begin{tabular}{|c|c|c|c|c|c|c|}
\hline & \multicolumn{6}{|c|}{ Team Sports } \\
\hline & $n$ & $\min$ & $\max$ & $M \pm S D$ & $M D$ & $S E$ \\
\hline RSA & 115 & 1.6 & 4.2 & $2.66 \pm 0.46$ & 2.6 & 0.0429 \\
\hline EPE & 115 & 1 & 5 & $1.82 \pm 0.69$ & 1.6 & 0.0643 \\
\hline SD & 115 & 1 & 3.6 & $1.69 \pm 0.62$ & 1.6 & 0.0578 \\
\hline \multirow[t]{3}{*}{ BT } & 115 & 1.27 & 3.4 & $2.06 \pm 0.44$ & 2 & 0.041 \\
\hline & \multicolumn{6}{|c|}{ Individual Sports } \\
\hline & $\mathbf{n}$ & $\min$ & $\max$ & $M \pm S D$ & $M D$ & $S E$ \\
\hline RSA & 108 & 1.8 & 3.8 & $2.86 \pm 0.49$ & 2.8 & 0.0472 \\
\hline EPE & 108 & 1 & 5 & $2.15 \pm 0.77$ & 2 & 0.0741 \\
\hline SD & 108 & 1 & 4.4 & $1.86 \pm 0.76$ & 1.8 & 0.0731 \\
\hline $\mathrm{BT}$ & 108 & 1.27 & 4.13 & $2.29 \pm 0.53$ & 2.2 & 0.051 \\
\hline
\end{tabular}

Note: $\mathrm{Min}=$ minimum. $M D=$ median. $M=$ mean. $S D=$ standard deviation. $\max =$ maximum. $S E=$ standard error, RSA $=$ Reduced Sense of Accomplishment, EPE $=$ Emotional and Physical Exhaustion, $\mathrm{SD}=\mathrm{Sport}$ Devaluation, BT $=$ Burnout Total

Table 2. Normality test and p-value in each group

\begin{tabular}{cccccc}
\hline Variable & $\boldsymbol{p}$ & $\begin{array}{c}\text { Normality Team } \\
\text { Sports }\end{array}$ & $\begin{array}{c}\text { Normality } \\
\text { Individual Sports }\end{array}$ & $\begin{array}{c}\text { CI } \\
\text { Team Sports }\end{array}$ & $\begin{array}{c}\text { CI } \\
\text { Individual Sports }\end{array}$ \\
\hline EPE & 0.001 & 0 & 0 & $1.6 ; 1.8$ & $2.0 ; 2.2$ \\
RSA & 0.006 & 0.02 & 0.005 & $2.6 ; 2.8$ & $2.6 ; 3.0$ \\
SD & 0.163 & 0 & 0 & $1.4 ; 1.8$ & $1.6 ; 2.0$ \\
BT & 0.001 & 0.001 & 0.001 & $1.93 ; 2.07$ & $2.13 ; 2.27$ \\
\hline
\end{tabular}

Note: $\mathrm{RSA}=$ Reduced Sense of Accomplishment, $\mathrm{EPE}=$ Emotional and Physical Exhaustion, $\mathrm{SD}=$ Sport Devaluation, $\mathrm{BT}=$ Burnout Total

Statistically significant differences were observed in Emotional Physical and Exhaustion (EPE) scores among athletes belonging to collective modalities and individual modalities. Through the Confidence Interval (CI) presented above, we observe for collective modality values between 1.6 and 1.8 and for individual modalities between 2.0 and 2.2.

However, for the variables Burnout Total (BT) and Reduced Sense of Accomplishment (RSA), there was a small difference between the groups. For the Burnout Total (BT) variable, the individual modal athletes present a higher median value $(2.13 ; 2.27)$ than the collective modality (1.93; 2.07). For the Reduced Sense of Accomplishment (RSA), individual athletes had a higher median score $(2.6 ; 3.0)$ than individuals in the collective modality $(2.6 ; 2.8)$. For the dimension Sport Devaluation (SD), there was no significant difference between the groups.

According to the descriptive analysis regarding sex, it is clear that the means and minimum values between groups are very close, as can be observed in Table 3.

In the case of the minimum values, Emotional and Physical Exhaustion (EPE), Sport Devaluation (SD) and Burnout Total (BT) have identical values. In relation to the means of the two groups, Burnout Total (BT) and Emotional and Physical Exhaustion (EPE) also have identical values, being 1.8 and 2.07, respectively. On the other hand, the variables Reduced Sense of Accomplishment (RSA) and Sport Devaluation (SD), have only a small variation of values between the groups, so there is no significant difference. 
Table 3. Descriptive values for each variable in relation to sex group

\begin{tabular}{lcccccc}
\hline & \multicolumn{7}{c}{ Female } \\
\cline { 2 - 7 } & $\boldsymbol{n}$ & $\boldsymbol{m i n}$ & $\mathbf{m a x}$ & $\boldsymbol{M} \pm \boldsymbol{S D}$ & $\boldsymbol{M D}$ & $\boldsymbol{S} \boldsymbol{E}$ \\
\cline { 2 - 7 } RSA & 50 & 1.8 & 3.8 & $2.81 \pm 0.51$ & 2.8 & 0.07 \\
EPE & 50 & 1 & 4 & $2.01 \pm 0.71$ & 1.8 & 0.10 \\
SD & 50 & 1 & 4 & $1.79 \pm 0.84$ & 1.4 & 0.12 \\
BT & 50 & 1.27 & 3.6 & $2.2 \pm 0.57$ & 2.07 & 0.08 \\
\cline { 2 - 7 } & $\boldsymbol{n}$ & $\mathbf{m i n}$ & $\mathbf{m a x}$ & $\boldsymbol{M} \pm \boldsymbol{S D}$ & $\boldsymbol{M D}$ & $\boldsymbol{S E}$ \\
& 173 & 1.6 & 4.2 & $2.74 \pm 0.47$ & 2.7 & 0.035 \\
RSA & 173 & 5 & $1.97 \pm 0.76$ & 1.8 & 0.05 \\
EPE & 173 & 1 & 4.4 & $1.77 \pm 0.65$ & 1.6 & 0.04 \\
SD & 173 & 1.27 & 4.13 & $2.16 \pm 0.48$ & 2.07 & 0.03 \\
BT & 173
\end{tabular}

Note: Min $=$ minimum. $M D=$ median. $M=$ mean. $S D=$ standard deviation. $\max =$ maximum. $S E=$ standard error, RSA $=$ Reduced Sense of Accomplishment, EPE $=$ Emotional and Physical Exhaustion, $\mathrm{SD}=\mathrm{Sport}$ Devaluation, BT $=$ Burnout Total

Table 4. p-value test for difference in relation to groups

\begin{tabular}{cccccc}
\hline Variable & $\boldsymbol{p}$ & Normality- F & Normality- M & CI F & CI M \\
\hline RSA & 0.47 & 0.08 & 0.005 & $2.6 ; 3.0$ & $2.6 ; 2.8$ \\
\hline SD & 0.55 & 0 & 0 & $1.2 ; 2.0$ & $1.6 ; 1.8$ \\
\hline EPE & 0.576 & 0.024 & 0 & $1.8 ; 2.2$ & $1.8 ; 2.0$ \\
\hline BT & 0.893 & 0.021 & 0 & $1.93 ; 2.27$ & $2.0 ; 2.17$ \\
\hline
\end{tabular}

Note: CI F = Confidence Interval of Female Group, CI M = Confidence Interval of Male Group, RSA = Reduced Sense of Accomplishment, EPE = Emotional and Physical Exhaustion, $\mathrm{SD}=$ Sport Devaluation, BT = Burnout Total

These data are best demonstrated in Table 4, with the values of the tests applied, and easily identified in the Confidence Intervals (CI).

For the variable Reduced Sense of Accomplishment (RSA), Sport Devaluation (SD) and Emotional and Physical Exhaustion (EPE), female athletes presented a relatively higher median value $(2.6 ; 3.0 ; 1.2 ; 2.0 ; 1.8 ; 2.2)$ in $(2.6 ; 2.8 ; 1.6 ; 1.8 ; 1.8 ; 2.2)$, respectively, but there was no significant difference. For the Burnout Total variable (BT), the differences between male athletes and female athletes fell further, reinforcing that there was no statistical difference between the groups.

A dispersion diagram between the age and three dimensions analyzed for burnout and Burnout Total values is shown below, followed by a line representing the fit of a linear regression between the pairs of variables (Figure 1). 


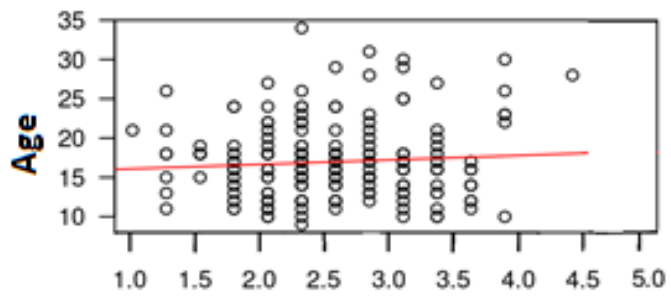

RSA

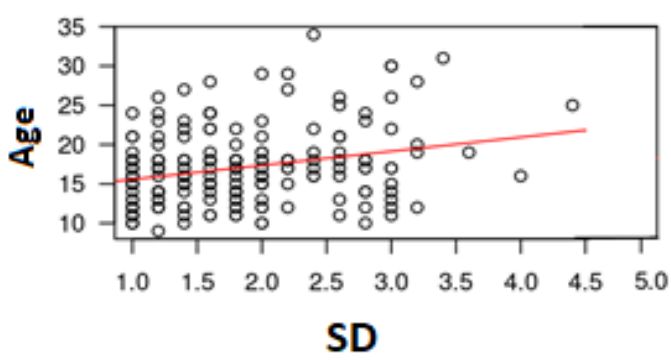

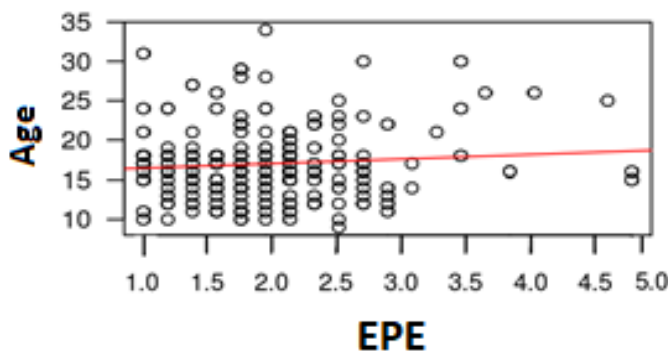

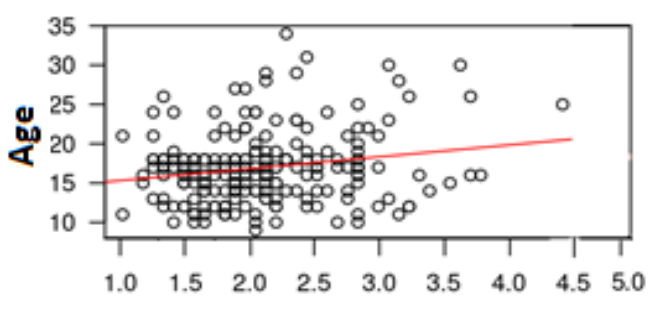

BT

Figure 1. Dispersion diagram of chronological age and burnout scales Note: RSA $=$ Reduced Sense of Accomplishment, EPE = Emotional and Physical Exhaustion, $\mathrm{SD}=$ Sport Devaluation, $\mathrm{BT}=$ Burnout Total

It was found that there is no strong linear relationship between all pairs of variables since the distribution is close to a cloud of points. However, for the variable age in relation to Sport Devaluation (SD) and Burnout Total (BT), a slight positive trend is noticed, which is more easily noticed in Table 5 with the values of the correlation coefficient.

Table 5. Pearson Correlation of age and burnout subscales

\begin{tabular}{ccc}
\hline Subscales & Correlation & p-value \\
\hline SD & 0.28 & 0.00003 \\
\hline EPE & 0.09 & 0.18043 \\
\hline RSA & 0.08 & 0.23991 \\
\hline BT & 0.20 & 0.00294 \\
\hline
\end{tabular}

Note: $\mathrm{RSA}=$ Reduced Sense of Accomplishment, $\mathrm{EPE}=$ Emotional and Physical Exhaustion, $\mathrm{SD}=$ Sport Devaluation, $\mathrm{BT}=$ Burnout $\mathrm{Total}$

The variables Sport Devaluation (SD) and Burnout Total (BT) obtained statistical significance, and a positive correlation, that is, individuals with greater age tended to have higher scores in these dimensions, however, the level of this correlation can be said to be "weak", since the correlation value was 0.28 for SD and 0.20 for BT. On the other hand, the variables Emotional and Physical Exhaustion (EPE) and Reduced Sense of Accomplishment (RSA) did not obtain significant difference, obtaining values of 0.09 and 0.08 respectively.

\section{DISCUSSION}

In the first comparative analysis, among athletes of individual and collective sports, in all aspects related to syndrome - Reduced Sense of Accomplishment (RSA), Emotional and Physical Exhaustion (EPE), Sport Devaluation (SD), Burnout Total the group of subjects from individual sports obtained the highest scores. Despite the few comparative studies among sports types, this result confirms one of the initial hypotheses, corroborating also the studies by (Kang et al., 2016) 
and (Madigan et al., 2016), in which individual sports athletes also obtained results higher, and according to the researchers, this result occurs because athletes have, for the most part, fewer interpersonal relationships, are also extremely perfectionists, suffer great pressure for results, and there is still no division of tasks and responsibilities (as in collective sports).

As also observed in the results above, some athletes had a maximum score for the Emotional and Physical Exhaustion (EPE), both in the group of sport and individual sports, showing that we must be careful, and investigate in a deeper and specific way the impact of this occurrence. In collective sports, one must also investigate the impact that these players with higher burnout scores represent for the team, and how important they are in relation to the group. It is noted in the present research that, even during the pre-competitive phase, high burnout scores for Emotional and Physical Exhaustion (EPE) were observed, and these results would be expected during the competition phase, where the rigid routine of training and games, higher pressure for a positive results, coming from several sources, would consequently cause greater physical and emotional exhaustion (Gustafsson et al., 2016; Verardi et al., 2015). These results obtained were similar to those found in other studies (Gustafsson et al., 2007), and reveals the need for new studies related to individual and collective sports, mainly involving a larger number of sports, proposing to investigate the athletes throughout the season.

The hypothesis that the female athletes would present a higher level, showing a greater vulnerability to Burnout Syndrome, was not confirmed. When comparing the male and female athletes the results show that there were no statistically significant differences related to the burnout scores in the three dimensions: Reduced Sense of Accomplishment, Emotional and Physical Exhaustion and Sports Devaluation. However, more studies are needed to determine differences in burnout levels between female and male athletes.

In addition, the data presented in an interesting way, as the few studies presented in the literature, found an inverse correlation with the age, sex, age, with younger athletes getting the highest scores for burnout. In the present study, the results show no correlation between age and the three dimensions of burnout. Although the literature also states that sports practice time as well as a higher age of athletes is related to lower burnout scores due to more adequate personal coping strategies (American Academy of Pediatrics, 2000; Brenner et al., 2016, 2007; Gustafsson et al., 2007), this was not possible to identify in the present study, since no data related to the level of experience and personal coping strategies were raised. And the very definition of professional experience, age and time of professional practice should be better explored, and none of these factors are clear in the literature, showing one more gap for future research.

Given the great practical implication, these results demonstrate the importance of investigating Burnout Syndrome in athletes, the nature of the sport (individual or collective), the differences between the sexes and the sports experience learned over the years. Thus, it is necessary to understand these aspects on the part of parents, teachers, and technicians.

Some limitations of the current study, one of them was the use of a convenience sample, it was composed only of two collective modalities and two individual modalities, which prevents the generalization of the results. Another aspect to be highlighted is that this study was characterized as transversal, once the measures were performed only once, during the pre-competitive phase, however, athletes may manifest during the competitive phase greater intensity in the perception of the feelings related to burnout.

It was concluded that the athletes belonging to the individual modalities had higher levels of Emotional and Physical Exhaustion when compared to those of collective modalities. This result suggests that, in the present study, individual athletes demonstrated greater vulnerability to burnout. When comparing the male and female athletes the results show that there were no differences between the scores in the three dimensions of burnout. It was also found that age did not influence burnout levels. 


\section{REFERENCES}

American Academy of Pediatrics. (2000). Intensive Training and Sports Specialization in Young $\begin{array}{lllll}\text { Athletes. } & \text { Pediatrics } & \text { 106). } & \text { Retrieved }\end{array}$ https://pediatrics.aappublications.org/content/pediatrics/106/1/154.full.pdf

Brenner, J. S., \& Council On Sports Medicine And Fitness (2016). Sports specialization and intensive training in young athletes. Pediatrics, 138(3), e20162148. https://doi.org/10.1542/peds.2016-2148

Brenner, J. S., \& Council On Sports Medicine And Fitness (2007). Overuse injuries, overtraining, and burnout in child and adolescent athletes. Pediatrics, 119(6), 1242-1245. https://doi.org/10.1542/peds.2007-0887

dos Santos, P. B., Kuczynski, K. M., Machado, T. D. A., Osiecki, A. C. V., \& Stefanello, J. M. F. (2014). Psychophysiological stress in under-17 soccer players. Journal of Exercise Physiology Online, 17(2), 67-79.

Goodger, K., Gorely, T., Lavallee, D., \& Harwood, C. (2007). Burnout in sport: A systematic review. The Sport Psychologist, 21(2), 127-151. https://doi.org/10.1123/tsp.21.2.127

Gustafsson, H., Hill, A. P., Stenling, A., \& Wagnsson, S. (2016). Profiles of perfectionism, parental climate, and burnout among competitive junior athletes. Scandinavian Journal of Medicine and Science in Sports, 26(10), 1256-1264. https://doi.org/10.1111/sms.12553

Gustafsson, Henrik, Kenttä, G., Hassmén, P., \& Lundqvist, C. (2007). Prevalence of burnout in competitive adolescent athletes. Sport Psychologist, 21(1), 21-37. https://doi.org/10.1123/tsp.21.1.21

Kang, K. D., Hannon, J. C., Haverson, A., Lee, J. W., Nam, J. J., \& Han, D. H. (2016). Perfectionism and burnout in women professional golfers. F Sports Medicine and Physical Fitness, 56(9), 1077-1085.

Madigan, D. J., Stoeber, J., \& Passfield, L. (2016). Motivation mediates the perfectionism-burnout relationship: A three-wave longitudinal study with junior athletes. Journal of Sport and Exercise Psychology, 38(4), 341-354.

Maslach, C., \& Jackson, S. E. (1981). The measurement of experienced burnout. Journal of Organizational Behavior, 2(2), 99-113. https://doi.org/10.1002/job.4030020205

Pires, D. A., Brandão, M. R. F., \& Silva, C. B. (2006). Validação do questionário de burnout para atletas, Journal of Physical Education, $17(1), \quad 27-36$. https://doi.org/10.4025/reveducfisv17n1p27-36

Raedeke, T. D., \& Smith, A. L. (2001). Development and preliminary validation of an athlete burnout measure. Journal of Sport and Exercise Psychology, 23(4), 281-306. https://doi.org/10.1123/jsep.23.4.281

Smucny, M., Parikh, S. N., \& Pandya, N. K. (2015). Consequences of single sport specialization in the pediatric and adolescent athlete. Orthopedic Clinics of North America, 46(2), 249-258. https://doi.org/10.1016/j.ocl.2014.11.004

Verardi, C. E. L., Nagamine, K. K., Neiva, C. M., Pessôa Filho, D. M., Domingos, N. A. M., Ciolac, E. G., \& Miyazaki, M. C. O. S. (2014). Burnout and playing position: A study of brazilian soccer players. Journal of Physical Education \& Sport, 14(3), 324-330. https://doi.org/10.7752/jpes.2014.03049

Verardi, Carlos Eduardo Lopes, Nagamine, K. K., Domingos, N. A. M., De Marco, A., \& De Oliveira Santos Miyazaki, M. C. (2015). Burnout and pre-competition: A study of its occurrence in brazilian soccer players. Revista de Psicologia Del Deporte, 24(2), 259-264.

Weinberg, R. S., \& Gould, D. (2018). Foundations of Sport and Exercise Psychology (7th ed.). Human Kinetics. 